\title{
Subgrid Precipitation Properties of Mesoscale Atmospheric Systems Represented by MODIS Cloud Regimes
}

\author{
JACKSON TAN \\ Universities Space Research Association, Columbia, and NASA Goddard Space Flight Center, Greenbelt, Maryland \\ LAZAROS OREOPOULOS \\ Earth Sciences Division, NASA Goddard Space Flight Center, Greenbelt, Maryland
}

(Manuscript received 30 August 2018, in final form 17 January 2019)

\begin{abstract}
The distribution of mesoscale precipitation exhibits diverse patterns: precipitation can be intense but sporadic, or it can be light but widespread. This range of behaviors is a reflection of the different weather systems in the global atmosphere. Using MODIS global cloud regimes as proxies for different atmospheric systems, this study investigates the subgrid precipitation properties within these systems. Taking advantage of the high resolution of Integrated Multisatellite Retrievals for GPM (IMERG; GPM is the Global Precipitation Measurement mission), precipitation values at $0.1^{\circ}$ are composited with each cloud regime at $1^{\circ}$ grid cells to characterize the regime's spatial subgrid precipitation properties. The results reveal the diversity of the subgrid precipitation behavior of the atmospheric systems. Organized convection is associated with the highest grid-mean precipitation rates and precipitating fraction, although on average only half the grid is precipitating and there is substantial variability between different occurrences. Summer extratropical storms have the next highest precipitation, driven mainly by moderate precipitation rates over large areas. These systems produce more precipitation than isolated convective systems, for which the lower precipitating fractions balance out the high intensities. Most systems produce heavier precipitation in the afternoon than in the morning. The grid-mean precipitation rate is also found to scale with the fraction of precipitation within the grid in a faster-than-linear relationship for most systems. This study elucidates the precipitation properties within cloud regimes, thus advancing our understanding of the precipitation structures of these atmospheric systems.
\end{abstract}

\section{Introduction}

The diversity of mesoscale atmospheric systems generates a range of precipitation patterns. Some of these patterns may be intense but localized, while some may be light but widespread, and some may possess a mixture of both. This complex range of patterns, driven by a myriad of dynamical and thermodynamical environments, complicates studies of their occurrences, properties, and relationship to each other and to the wider circulations of the climate system. Categorizing these precipitation patterns globally in an objective fashion is a challenge.

Cloud regimes (CRs; also called weather states) provide an effective way of classifying atmospheric systems into a discrete set of states (Jakob and Tselioudis 2003;

\footnotetext{
Corresponding author: Jackson Tan, jackson.tan@nasa.gov
}

Rossow et al. 2005). By identifying recurring patterns in the distribution of cloud properties, the global atmosphere can be categorized into 10 to 12 CRs (Tselioudis et al. 2013; Oreopoulos et al. 2014, 2016). In grouping together cloud patterns that are similar, CRs can overcome inconsequential differences arising from minor variations and measurement uncertainties, and capture the essence of underlying mesoscale phenomena. CRs have proven valuable as tools to improve our understanding of the weather and climate, such as the radiative and heating effects in various cloud fields (Oreopoulos and Rossow 2011; Haynes et al. 2011; Li et al. 2013; Stachnik et al. 2013; Rossow et al. 2016), the dominant modes of variability in the climate system (Chen and Del Genio 2009; Tromeur and Rossow 2010; Tselioudis and Rossow 2011), the convective environments of phenomena such as African easterly waves (Mekonnen and Rossow 2011, 2018), the fidelity of 
climate models to the real world (Gordon et al. 2005; Williams et al. 2005; Williams and Tselioudis 2007; Williams and Webb 2009; Bodas-Salcedo et al. 2012; Tsushima et al. 2013; Bodas-Salcedo et al. 2014; Mason et al. 2015; Tsushima et al. 2016; Jin et al. 2017; Tan et al. 2018a), and changes in climate processes (Tselioudis et al. 2010; Sohn et al. 2013; Tan et al. 2015).

Given the intimate relationship between clouds and precipitation, the grid-mean precipitation properties of CRs have been studied extensively. For example, Lee et al. (2013), Tan et al. (2013), and Oreopoulos et al. (2014) investigated the precipitation properties associated with several tropical and global CRs, finding that the CRs possess distinct distributions of precipitation rates. Oreopoulos et al. (2017b) further used the CRs to diagnose the complex aerosol invigoration effects on precipitating cloud systems. Tan et al. (2018a) examined the degree to which climate models are able to reproduce the precipitation associated with the CRs, identifying deficiencies in representing organized convective precipitation and the existence of compensating errors. Rossow et al. (2013) focused on extreme precipitation, demonstrating that most of the heavy rainfall in the tropics is associated with the CR representing organized convection. Tan et al. (2015) used this CR to associate recent increases in tropical precipitation with the increase in frequency of organized convection.

While such grid-mean quantification of CR precipitation is informative in characterizing its nature, it cannot resolve questions on the precipitation structure within the CR. For example, what fraction of the area occupied by the CR is precipitating? What drives the high grid-mean precipitation rates of organized convection: intense convective precipitation or widespread stratiform precipitation? Or more generally, what is the interplay between grid-mean precipitation rates and subgrid precipitating fraction in different atmospheric systems? How do extratropical precipitation systems compare with those in the tropics? Jakob and Schumacher (2008) investigated the convective and stratiform precipitation of various CRs in the tropical west Pacific, providing some insights into their subgrid precipitation properties. For example, they found that only one CR, representing organized convection and having the highest precipitation rates, is associated with more stratiform precipitation than convective precipitation. However, the study was limited in scope geographically and in its temporal resolution (daytime average). Motivated by the lack of a global characterization of precipitation through the CRs, this study aims to leverage the availability of a high-resolution precipitation dataset to investigate the subgrid precipitation properties of the global CRs. The goal of this study is to improve the identification of the atmospheric systems the CRs represent, and by proxy to better understand the precipitation patterns of these systems.

\section{Data and approach}

\section{a. MODIS cloud regimes}

The concept of the cloud regime has its genesis in the International Satellite Cloud Climatology Project (ISCCP), where it is sometimes referred to as "weather states." By aggregating passive observations of cloudtop pressure and cloud optical thickness into joint histograms and applying a $k$-means clustering algorithm, the complex cloud fields can be classified into a discrete number of states (Jakob and Tselioudis 2003; Rossow et al. 2005). Therefore, CRs can be thought of as groups of ISCCP scenes with similar cloud distributions. Numerous studies have examined the properties and atmospheric states of the ISCCP CRs, demonstrating that they represent distinct environments in the atmosphere (Jakob et al. 2005; Jakob and Schumacher 2008; Tan et al. 2013; Handlos and Back 2014; Mason et al. 2014).

In this study, we choose to use CRs defined from Moderate Resolution Imaging Spectroradiometer (MODIS) observations due to several retrieval advantages over ISCCP. These include higher pixel resolution $(\sim 5 \mathrm{~km}$ for cloud-top pressure and $\sim 1 \mathrm{~km}$ for optical thickness compared to $\sim 10$ to $\sim 30 \mathrm{~km}$ in ISCCP), more advanced techniques such as $\mathrm{CO}_{2}$ slicing for cloud-top identification due to available spectral channels, and greater retrieval consistency due to the use of identical instruments (two MODIS instruments compared to a changing network of geostationary and polar-orbiting satellites carrying different instruments). These advantages outweigh the main drawback of a more limited sampling in MODIS compared to ISCCP. Two MODIS instruments are currently in operation, both on low-Earth orbit satellites: Terra, with an equator crossing time of 1030 local time (LT), and Aqua, with an equator crossing time of 1330 local time. Aqua is also part of the A-Train constellation. MODIS produces ISCCP-like joint histograms at $1^{\circ}$ grids globally through the MOD08_D3 (Terra) and MYD08_D3 (Aqua) products (King et al. 2013) and global CRs have been defined through the $k$-means cluster algorithm (Oreopoulos et al. 2014, 2016).

The dataset of MODIS global CRs used here are based on MODIS Collection 6 Level-3 datasets. The clusters are obtained by applying the $k$-means algorithm to joint histograms from December 2002 to November 2014, and extended to March 2017 by assigning joint histograms in the subsequent period to the original 

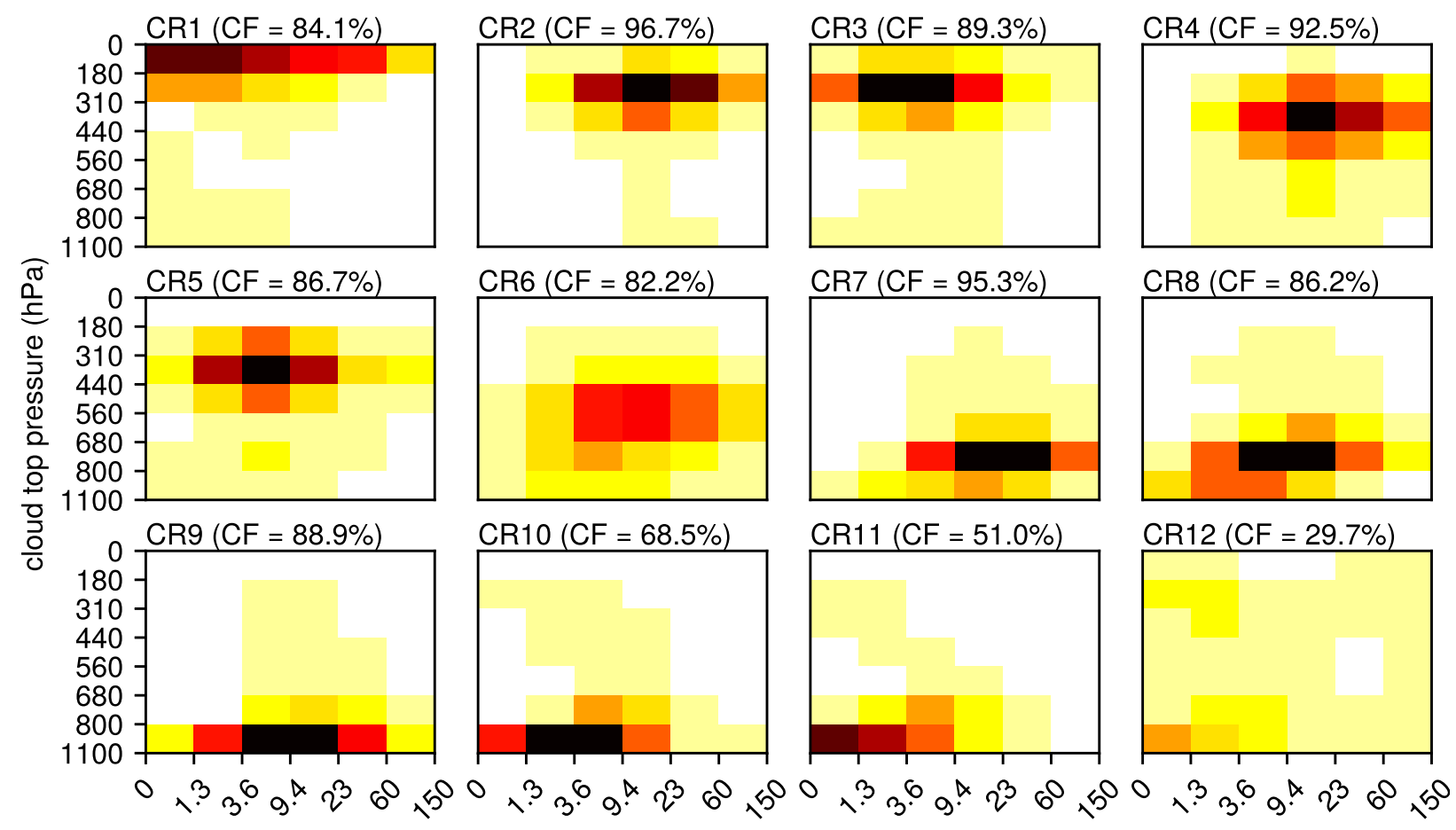

cloud optical thickness

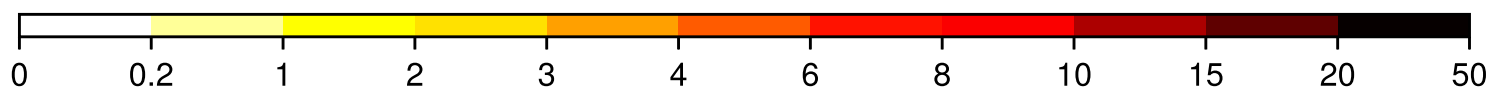

$(\%)$

FIG. 1. Centroids (mean joint histograms) of the 12 MODIS CRs. CF indicates the cloud fraction of the centroid obtained by summing the bins of the joint histogram.

centroids. There are a total of 12 global CRs (excluding clear-sky grids) obtained through nested clustering (Oreopoulos et al. 2016). Note that because of several refinements introduced in Collection 6, including improvements to the retrieval algorithms and a change in the definition of "day" (Hubanks et al. 2018), the number of CRs has increased compared to Collection 5 (Oreopoulos et al. 2014). Figure 1 shows the centroids of these 12 CRs and Fig. 2 shows their global distribution of occurrence for April 2014 to March 2017. Many of these CRs have counterparts to the ISCCP global weather states (Tselioudis et al. 2013); for example, MODIS CR2 corresponds to ISCCP WS1. Table 1 summarizes the properties of the CRs and the interpretation of the physical systems they represent, based on the centroids, geographical distributions, and results in existing literature. Of particular note for precipitation are the first six CRs, all of which are systems typically associated with precipitation. Using active sensors, Leinonen et al. (2016) and Oreopoulos et al. (2017a) verified that the cloud profiles of the CRs are reasonably well captured by the mean cloud patterns (Fig. 1), although Leinonen et al. (2016) found some regional differences arising from different meteorological conditions.

\section{b. IMERG}

The Integrated Multisatellite Retrievals for GPM (IMERG) is the high-resolution precipitation dataset from the Global Precipitation Measurement (GPM) mission (Huffman et al. 2018). The IMERG algorithm combines precipitation estimates from microwave sensors on board a constellation of low-Earth orbit satellites, uses Lagrangian interpolation and the lowerquality geosynchronous IR-based precipitation to fill in the gaps, and implements a surface gauge adjustment scheme to correct for bias. This allows IMERG to provide precipitation estimates at an unprecedented resolution of $0.1^{\circ}$ every half-hour globally. In this study, we select the gauge-adjusted precipitation estimate from the Final run in IMERG V05, which provides estimates beginning April 2014 within $\pm 60^{\circ}$ latitudes.

IMERG is composited with MODIS CRs from Terra and Aqua to obtain the subgrid precipitation values within the CRs, which are resolved at $1^{\circ}$. In the case of 

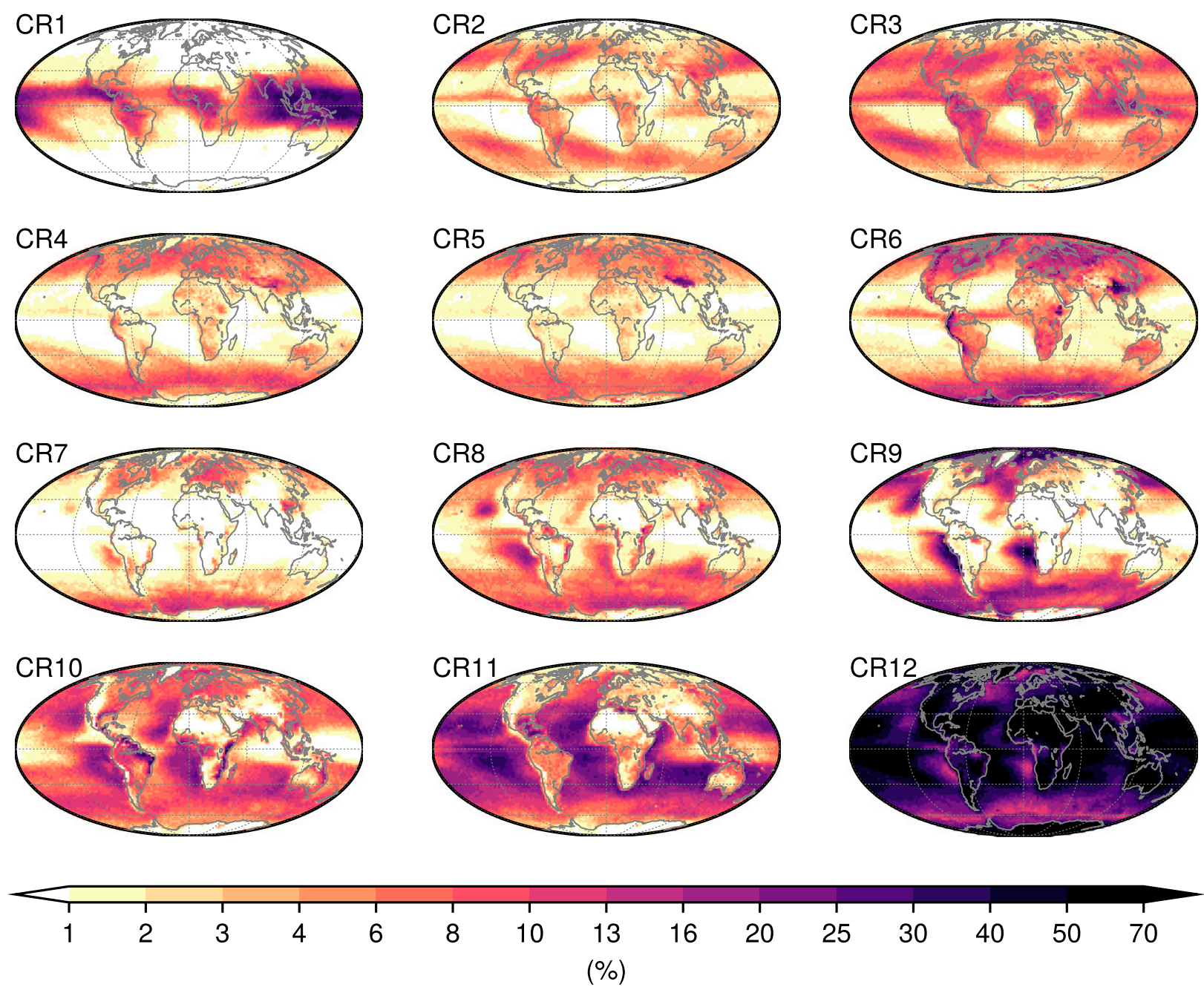

FIG. 2. Geographical distribution of the 12 MODIS CRs for the period considered in this study (April 2014-March 2017).

Aqua, the spacecraft carrying the MODIS instrument and the GCOM-W1 satellite carrying the AMSR2 microwave sensor used in IMERG are both flying in the A-Train formation. As a result, MODIS CRs from Aqua are mostly composited with precipitation estimates from AMSR2. On the other hand, MODIS CRs from Terra are composited with precipitation estimates from all other sources including the Lagrangian interpolation and IR precipitation. While the precipitation estimates from the different microwave sources have been intercalibrated to ensure consistency, differences may still arise due to instrument sensitivity, resolution, and scan strategy. Since AMSR2 is one of the higher-resolution and more accurate sensors in the GPM constellation (Tan et al. 2018b), the precipitation of Aqua MODIS CRs is expected to be slightly better resolved than that of Terra MODIS CRs.
As with all spaceborne passive retrievals of precipitation, IMERG possesses considerable uncertainty. However, this is generally not a problem, because random errors can be reduced by aggregating precipitation estimates-as will be done in this study for each CRand systematic errors are ameliorated with the intercalibration and gauge adjustment. Nevertheless, there are situations for which IMERG retrievals may be inaccurate. First, the IR-based precipitation has been shown to be significantly less accurate than microwavebased retrievals (Tan et al. 2016). Second, over frozen surfaces, microwave-based retrievals struggle to identify precipitation and IMERG reverts to IR-based precipitation in such situations (Huffman et al. 2018). Third, retrievals over land rely primarily on the scattering signal of ice precipitation aloft, which may pose problems for shallow (warm) precipitation. Fourth, the retrieval of frozen precipitation remains an area of active research 
TABLE 1. Key properties of the MODIS CRs. RFO indicates its daily relative frequency of occurrence over the period used in this study. CF indicates mean cloud fraction.

\begin{tabular}{|c|c|c|c|}
\hline & Interpretation & RFO (\%) & $\mathrm{CF}(\%)$ \\
\hline CR1 & $\begin{array}{l}\text { Isolated convection in tropics with } \\
\text { large cirrus coverage }\end{array}$ & 4.79 & 84.1 \\
\hline $\mathrm{CR} 2$ & $\begin{array}{l}\text { Organized convection in tropics } \\
\text { and midlatitudes }\end{array}$ & 3.65 & 96.7 \\
\hline CR3 & $\begin{array}{l}\text { Less organized convection, possibly } \\
\text { remnants of organized convection }\end{array}$ & 6.13 & 89.3 \\
\hline CR4 & $\begin{array}{l}\text { Extratropical storms (generally } \\
\text { summer) }\end{array}$ & 3.75 & 92.5 \\
\hline CR5 & $\begin{array}{l}\text { Extratropical storms (generally } \\
\text { winter) }\end{array}$ & 3.38 & 86.7 \\
\hline CR6 & $\begin{array}{l}\text { Tropical congestus and mid- to high- } \\
\text { latitude nimbostratus }\end{array}$ & 5.22 & 82.2 \\
\hline CR7 & $\begin{array}{l}\text { Thick stratus predominantly in } \\
\text { extratropics }\end{array}$ & 1.96 & 95.3 \\
\hline CR8 & $\begin{array}{l}\text { Boundary layer stratocumulus and } \\
\text { thick cumulus fields }\end{array}$ & 4.58 & 86.2 \\
\hline CR9 & Shallow marine stratocumulus fields & 5.97 & 88.9 \\
\hline CR10 & $\begin{array}{l}\text { Decaying marine stratocumulus and } \\
\text { cumulus fields }\end{array}$ & 7.74 & 68.5 \\
\hline CR11 & Shallow and trade cumulus & 11.93 & 51.0 \\
\hline CR12 & $\begin{array}{l}\text { Low cloud fraction regime with no } \\
\text { characteristic shape }\end{array}$ & 40.89 & 29.7 \\
\hline
\end{tabular}

(Skofronick-Jackson et al. 2017), so the quantification of snowfall rates is less reliable than of rainfall rates with evidence of underestimation (Wen et al. 2016). These situations do not affect most of the estimates in this study, but their effects will be mentioned where relevant.

\section{c. Compositing IMERG to CRs}

The MODIS CRs are defined on a $1^{\circ}$ grid during sunlit hours at the daily time scale. This resolution is inherited from the MOD08_D3 and MYD08_D3 products. However, a daily time scale will mask any diurnal variability and introduce significant geolocation errors when compositing IMERG with these instantaneous observations of clouds. Therefore, we use the mean solar zenith angle, provided in the MOD08_D3 and MYD08_D3 products, to infer the UTC time of each MODIS CR occurrence to further separate them into half-hour slices following the method described in Jin et al. (2018). By matching the time resolution of IMERG, we can observe the precipitation properties of MODIS observations in a way that best reflects their nominally instantaneous nature.

This mean solar zenith angle method, however, has a drawback. This is exemplified in Fig. 3, which shows the coverage of the MODIS instrument on Terra in six consecutive half-hour slices as inferred from the mean solar zenith angle in the gridded (Level 3) dataset
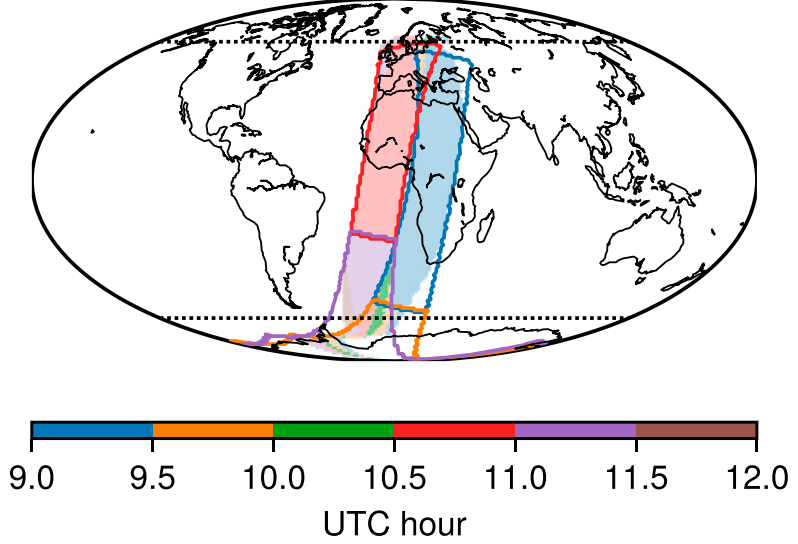

FIG. 3. Coverage of six consecutive half-hour observations from Terra MODIS observations from Level-2 (orbital) data (contours) and the half-hour slices for the same periods derived by applying the mean solar zenith angle method to the Level-3 (gridded) data (shaded areas). The dotted lines mark the $60^{\circ} \mathrm{N} / \mathrm{S}$ limit in this study.

(shaded areas) and as determined from the actual orbital (Level 2) retrievals at daytime (contours). Poleward of $23^{\circ} \mathrm{N} / \mathrm{S}$, observations from consecutive orbits-separated by about $100 \mathrm{~min}$-may overlap; consequently, the MODIS Level-3 gridded data in those overlapping areas will contain observations from different orbits. The mean solar zenith angle method is unable to separate such overlapping swaths. Moreover, in Fig. 3, there are areas in the Southern Hemisphere, which contains observations from 0900 to 0930 UTC (blue contour) and 1100 to 1130 UTC (purple contour), such that the mean solar zenith angle corresponds to 1000 to 1030 UTC (green shading) - when Terra is on the ascending nighttime mode. These artifacts are unavoidable limitations of using the daily gridded dataset from which the CRs are derived. However, while some grid boxes may be "contaminated" by observations from other times, we believe these effects are limited because 1) observations from other orbits tend to come from the outer swaths where there are fewer observations from the cross-track scanning MODIS, 2) cloud fields generally persist over durations longer than $100 \mathrm{~min}$, and 3) minor variations in the joint histogram are unlikely to change its CR membership. In contrast, using composites of daily CRs with daily precipitation rates will incur an uncertainty of up to 1 day. Therefore, despite the drawback of its inability to separate overlapping swaths, separating the CRs into half-hour slices using its mean solar zenith angle should provide a better temporal matching than using daily observations.

The half-hour compositing of IMERG with MODIS CRs entails a geolocation match between the $0.1^{\circ}$ precipitation estimates within the $1^{\circ} \mathrm{CR}$ grid. This means that each MODIS CR occurrence is composited with 
100 precipitation values $(10 \times 10$ spatial subgrids $)$. In this study, any mention of the grid or subgrid refers to the $1^{\circ}$ native scale of the MODIS joint histograms and therefore of the CRs. The overlapping period for the current MODIS and IMERG records is April 2014 to March 2017 ( $3 \mathrm{yr}$ ). This produces sufficient samples for the analyses in this study ( $>1$ million per CR), so a longer record-which will be available with the reprocessing of IMERG V06 back to 1998-is unnecessary for improving the statistical robustness of the results. While the $\pm 60^{\circ}$ latitude coverage limit is set by IMERG V05, restricting to $\pm 60^{\circ}$ helps to minimize the aforementioned artifact when separating daily MODIS data into smaller slices and the distortion of the equal-angle grid cell area at high latitudes.

\section{Results}

\section{a. Distribution of subgrid precipitation}

The focus of this study is on the subgrid precipitation properties of MODIS CRs. However, as a start, it is worthwhile to look at the grid-mean precipitation rate. This is a straightforward analysis that will inform us on the importance of the various CRs to global precipitation. Such analyses have been conducted for ISCCP CRs (Lee et al. 2013; Rossow et al. 2013; Tan et al. 2013) and MODIS Collection 5 CRs (Oreopoulos et al. 2014), although none has been performed for the MODIS Collection 6 CRs used here.

Figure 4 shows the distribution of grid-mean precipitation rates of all $12 \mathrm{CRs}$, with the values sorted into 51 logarithmically spaced bins between 0.01 and $10 \mathrm{~mm} \mathrm{~h}^{-1}$. It is immediately evident that CRs $1-6$ are associated with more precipitation than CRs 7-12. In particular, CR2, which represents organized convection, is associated with the highest amount of precipitation, consistent with previous studies (e.g., Rossow et al. 2013; Tan et al. 2013; Oreopoulos et al. 2014). CR1 and CR4 both have considerable amounts of precipitation as well, but CR4 has more precipitation below $2 \mathrm{~mm} \mathrm{~h}^{-1}$ while $\mathrm{CR} 1$ has more precipitation above that. CR3, CR5, and CR6 are clearly associated with lower precipitation. Despite the similarity between CR4 and CR5 in their representations of extratropical storms, their cloud structures, and annual geographical distributions, their precipitation distributions differ notably. However, with CR5 being a mostly winter occurrence (Oreopoulos et al. 2017a), the precipitation has a higher proportion of snow, which has higher uncertainty and possible underestimation in its retrievals (section 2b) and may play a part in the difference from CR4, which occurs mostly during summer (Oreopoulos et al. 2017a). Furthermore,

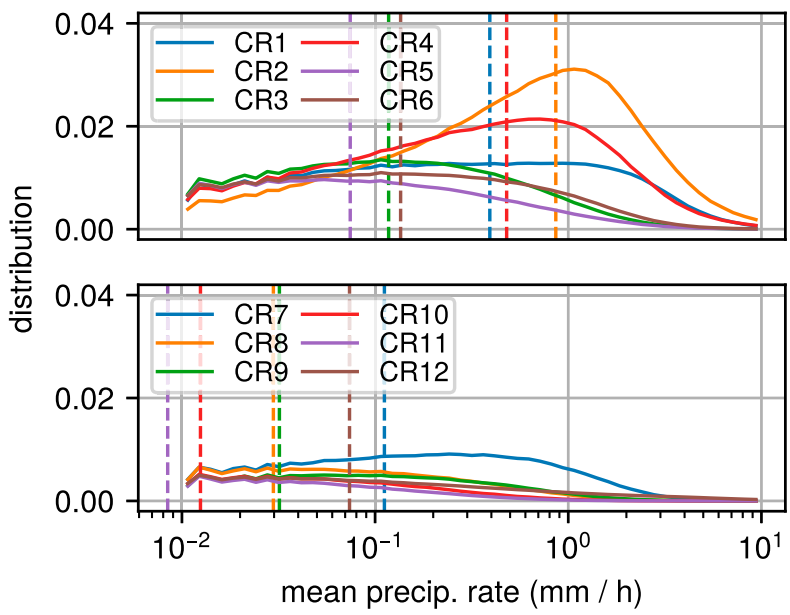

FIG. 4. Distribution of grid-mean precipitation rates for each MODIS CR, sorted into 51 logarithmically spaced bins from 0.01 to $10 \mathrm{~mm} \mathrm{~h}^{-1}$. The vertical dashed lines indicate the grid-mean precipitation rates averaged over all composites for each CR.

snowfall—or, to be precise, snow water equivalent-is typically less intense than rainfall, which may be a factor in the observed difference. CR7 and CR12, too, have average grid-mean precipitation rates that are comparable to CR3, CR5, and CR6. For CR7, which represents extratropical stratus clouds, there is an appreciable chance of precipitation up to about $3 \mathrm{~mm} \mathrm{~h}^{-1}$. For CR12, which represents a regime with low cloud fractions, the long tail in its distribution in Fig. 4 counterbalances the generally low chance of precipitation to give an average precipitation rate that is appreciable. Overall, Fig. 4 indicates that CRs 1-6 are the major players in global precipitation, although, as we will see later, the subgrid precipitation patterns of CRs 7-12 possess interesting features that are not readily apparent when averaged over the grid cell.

Another precipitation property we can examine by taking advantage of the high resolution of IMERG is the fraction of the $1^{\circ}$ grid with nonzero precipitation, or precipitating fraction. Figure 5 shows the distribution of precipitating fraction for each CR, sorted into 24 bins linearly spaced from 0.04 to 0.96 , as well as the average precipitating fraction for each CR. Comparing across all CRs, Fig. 5 reveals that the order of average precipitating fraction generally reflects that of the gridmean precipitation rates (Fig. 4), with CR2 being the highest, followed by CR4 and CR1, then CR3, CR5, and CR6. Surprisingly, CR7 and CR12 also have a relatively high precipitating fraction, respectively more so than and comparable to CR5. For CR12, this is notable because it deviates from the expectation that a low average grid-mean precipitation rate is associated with a low average precipitating fraction. Figure 5 indicates that, 


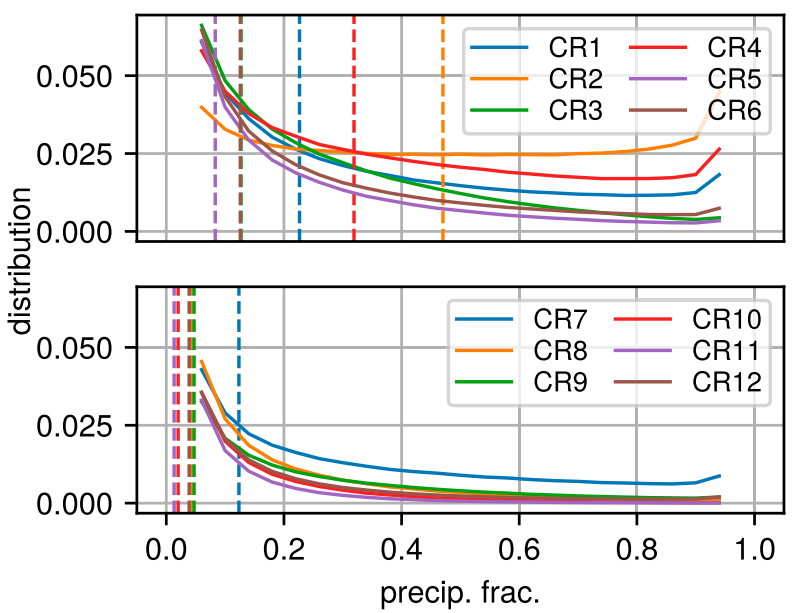

FIG. 5. Distribution of precipitating fraction for each MODIS $\mathrm{CR}$, sorted into 24 linearly spaced bins from 0.04 to 0.96 . Because the occurrences of 0 and 1 are very high, the bins containing them are not included to accentuate the distributions of values in between. The vertical dashed lines indicate the precipitating fractions averaged over all composites for each CR.

even for organized convection as represented by CR2, the average precipitating fraction is less than 0.5 . So, on average, less than half the grid cell of organized convection is precipitating, despite the near-complete cloud cover of CR2 (Table 1). While it is expected that cloud coverage is always higher than precipitation coverage, Fig. 5 reveals the degree of difference in these two quantities.

The distribution of precipitating fractions provides further insights into its variability (Fig. 5. For CR2, the distribution is roughly flat over much of the precipitating fraction values; this means that the likelihood of CR2 precipitating in, say, $25 \%$ of the grid is similar to that in $75 \%$ of the grid. This is an unexpected result that reveals how varied the subgrid precipitation pattern can beone would expect organized convection to have precipitation in about half the grid (as its average precipitating fraction suggests) more often than being mostly dry. Nevertheless, CR2 is unusually high in its precipitating fraction compared to other CRs, all of which have a peak at the lowest precipitating fraction bin and a declining frequency of occurrence at higher precipitating fractions. This is the case even for the generally "dry" CRs 8-12, indicating that even these suppressed states have a chance of some precipitation in a small area within the grid. It is possible, however, that the uncertainty around the retrievals of warm precipitation over land (section 2b) may lead to an underestimation of precipitating fraction.

However, not shown in Fig. 5 is a jump in many of the distributions at $100 \%$. The bin containing the $100 \%$ precipitating fraction is excluded so the differences in the curves between 0 and 1 are more visible. While a high occurrence of $0 \%$ precipitating fraction-or no subgrid precipitation-is expected, the reason for an increased occurrence of precipitation in the entire grid is unclear. A partial explanation lies with inherent aspects of IMERG. Some of the passive microwave sensors have resolutions that are coarser than the IMERG resolution; when projected onto the $0.1^{\circ}$ grids, these pixels are spatially "smeared" over multiple grid cells, resulting in lower intensities and higher precipitating areas. This is confirmed by the lower (but still elevated) occurrence of $100 \%$ precipitating fraction for Aqua CR occurrences (not shown), which are matched with IMERG precipitation heavily weighted to AMSR2 observations aboard the GCOM-W1 satellite that flies in formation with Aqua (section 2b).

The preceding analyses confirmed the intense precipitation associated with organized convection as represented by CR2, possessing high grid-mean precipitation rates and precipitating fraction. Even so, organized convection has, on average, precipitation in only half the grid cell. Summer extratropical storms, represented by CR4, are also associated with high amounts of precipitation, a sharp contrast to their winter counterparts, represented by CR5, despite similar cloud patterns and annual geographical distribution. CRs 7-12, which collectively represent nearly three-quarters of the occurrence of CRs, are generally dry, suppressed environments, although there is a chance of some precipitation in a small area within the grid.

\section{b. Relationship between grid-mean precipitation rate and subgrid precipitating fraction}

The previous section examined the grid-mean precipitation rates and the precipitating fractions separately. However, we would expect these two quantities to be related: as the fraction of the grid that is precipitating increases, the average precipitation rate over the grid should also rise. In this section, we study the relationship between these two variables.

Figure 6 shows a density scatter diagram of these two quantities for each CR, along with the 25th, 50th, and 75th percentiles as well as average grid-mean precipitation rate in each precipitating fraction bin of width 0.01. As expected, the higher the precipitating fraction, the higher the grid-mean precipitation rate on average. However, the relationship varies by CR. For CR1, CR2, and CR4, the average grid-mean precipitation rates as a function of precipitating fractions are higher than that of all other CRs except CR12, with grid-mean precipitation rates of about $2.5 \mathrm{~mm} \mathrm{~h}^{-1}$ on average when the entire grid is precipitating. In fact, notwithstanding the higher 


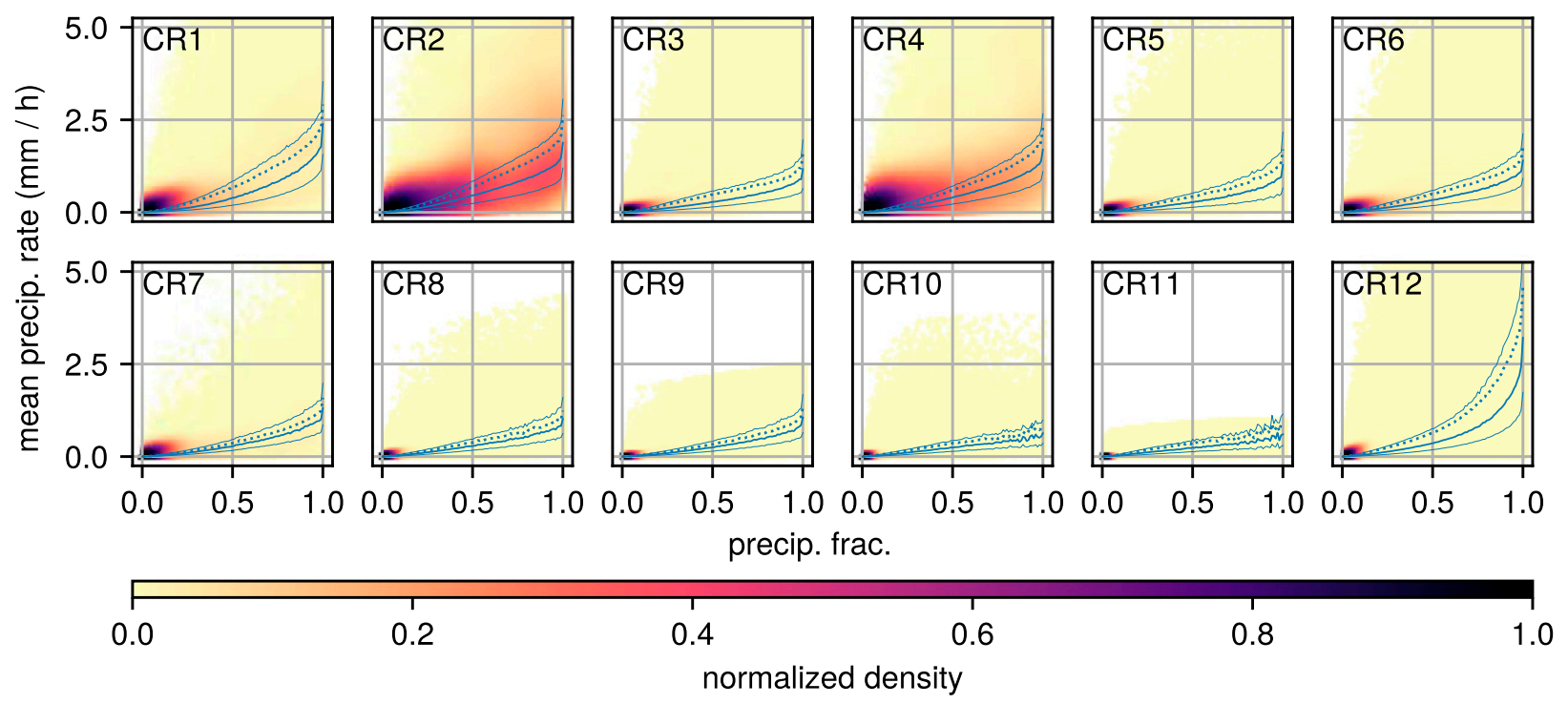

FIG. 6. Scatter diagram of grid-mean precipitation rates and precipitating fraction for each MODIS CR, with the colors indicating the density of points (based on Gaussian kernel density estimation). The blue lines indicate the 25th, 50th, and 75th percentiles (solid) and the mean (dotted) in each bin of precipitating fraction.

grid-mean precipitation of CR2 (Fig. 4), the average grid-mean precipitation rate of CR1 is similar to that of CR2 for the same precipitating fraction. This is possibly a reflection of the intense convection that is common to $\mathrm{CR} 1$ and $\mathrm{CR} 2$, which represent isolated convection and organized convection respectively. Of course, it is rarer for isolated convection than organized convection to cover a large area within the grid cell-as reflected in the lower density of points at high precipitating fraction in CR1 (Fig. 6)—so organized convection still produces more precipitation overall.

For CR4, the grid-mean precipitation rate as a function of precipitating fraction is, on close inspection, slightly lower than that of CR1 and CR2 (Fig. 6). This supports our interpretation that they represent extratropical storms, which are generally not as intense as tropical storms. Compared to the winter extratropical storms represented by CR5, the summer extratropical storms represented by CR4 have only just slightly higher grid-mean precipitation rate. Therefore, it is the higher precipitating fraction in CR4 (Fig. 5) that is the chief cause of the stark difference in grid-mean precipitation rates between these two systems.

The most striking and unexpected behavior is that of CR12, which has the highest average grid-mean precipitation rate in each bin of precipitating fraction, even more so than CR1 and CR2. While high precipitating fraction is rare in CR12, the average grid-mean precipitation rate is high when nearly the entire grid cell is precipitating. This is especially unexpected given that CR12 generally represents dry, suppressed conditions, as deemed from its low cloud fraction and centroid pattern. A likely explanation is as follows: with the highest relative frequency of occurrence, CR12 may represent a diversity of atmospheric systems - some of which may be associated with intense precipitation - that the clustering approach and hence the centroid in Fig. 1 can only represent to a limited extent. Indeed, this is the conclusion of Oreopoulos et al. (2017a), who found that CR12 can be further split into three subregimes, each with sufficiently distinctive properties and one of which contains substantial fraction of deep convective clouds according to CloudSat (see Fig. 9 therein). This is also supported by examining snapshots of the CR field, which clearly reveals "bits" of CR12 occurrence embedded within the large clusters of CR1 and CR2 occurrence in the tropical west Pacific (not shown).

Figure 6 also reveals an interesting property of subgrid-scale precipitation. Suppose each subgrid cell can only have a value of 0 or $1 \mathrm{~mm} \mathrm{~h}^{-1}$; this will result in a linear, one-to-one relationship between grid-mean precipitation rate and precipitating fraction. However, the curves in Fig. 6 show the grid-mean precipitation rate scaling with precipitating fraction at a faster-thanlinear rate for all CRs except CR10 and CR11. Physically, this means that, as precipitating fraction increases, the subgrid cells that are precipitating (or the average nonzero precipitation rate) are more intense. Investigating why this is so lies beyond the scope of our study, although we present several conjectures for its cause. One possibility is that favorable conditions, such as environments that are moister or convectively unstable, lead to both higher precipitating fraction and 

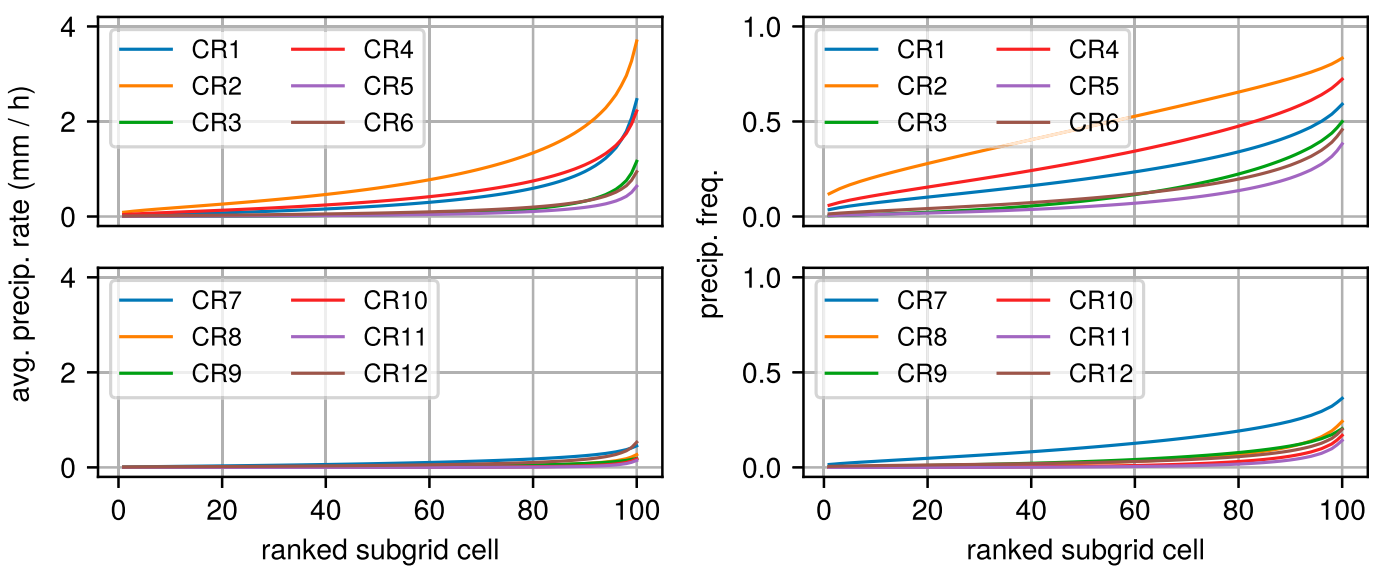

FIG. 7. (left) Average precipitation rates and (right) precipitating frequency in ranked subgrid cells for each MODIS CR. Rank 1 is the driest subgrid cell and rank 100 is the wettest subgrid cell.

more intense subgrid precipitation. Another possibility is that higher precipitating fraction leads to more favorable conditions (e.g., through congestus preconditioning for systems with convection; Hohenegger and Stevens 2013), which in turn leads to more intense subgrid precipitation. It is also possible, for some systems, that a dynamical feedback mechanism may be at play, such as the interactions between cold pools from convective precipitation and the formation of deep convective clouds (e.g., Feng et al. 2015). Regardless, it is clear that the majority of atmospheric systems share the same property of faster-than-linear scaling between precipitation intensity and precipitating fraction at the subgrid scale.

By simultaneously analyzing the grid-mean precipitation rate and the precipitating fraction for the MODIS CRs, we found that higher precipitating fraction is associated with higher grid-mean precipitation rate as expected, but the relation varies between CRs. Both isolated convection as represented by CR1 and organized convection as represented by CR2 have higher precipitation rates as a function of precipitating fractions than most other CRs. Extratropical storms have slightly more precipitation in summer (CR4) than in winter (CR5) for the same precipitating fraction. The "catch-all" CR12 possesses an anomalous behavior here, suggesting that further separation into subregimes is warranted. Finally, the nonlinear nature of the relationship between grid-mean precipitation rate and precipitation fraction for most of the CRs hints at possible correlated or feedback processes between the two.

\section{c. Ranked subgrid precipitation}

The sections have hitherto focused on the distributions of subgrid precipitation properties of the 12 MODIS CRs and, while informative, have lacked information on the subgrid structure of precipitation. In this section, we attempt to illuminate the subgrid precipitation structure by examining the precipitation properties in ranked subgrid cells. That is, we sort the 100 subgrid precipitation values of each composite from lowest to highest and keep track of the precipitation properties in each rank, from the driest subgrid cell (rank 1) to the wettest subgrid cell (rank 100). Note that equal precipitation values are sorted into consecutive ranks, so each composite assigns a value to all ranked subgrid cells.

Figure 7 (left) shows the average precipitation rate in each ranked subgrid cell. All CRs have approximately zero average precipitation rate in their driest subgrid cell. At the wettest end, CR1, CR2, and CR4 have differing but substantial precipitation. The other CRs have low precipitation rates even at the wettest subgrid cell. As expected, CR2 has the highest average precipitation rate in all ranked subgrid cell, with the wettest subgrid cell at $3.69 \mathrm{~mm} \mathrm{~h}^{-1}$. CR1 and CR4 have the next highest average precipitation rates, with CR1 having slightly lower rates at drier subgrid cells but marginally higher rates at wetter subgrid cells. This suggests that precipitation in CR1 is slightly more intense but also slightly more sporadic than CR4, consistent with the respective atmospheric systems (isolated convection versus summer extratropical storms) they represent.

Figure 7 (right) shows the frequency of nonzero precipitation, or precipitating frequency, in each ranked subgrid cell for the CRs. In the driest subgrid cell, most of the CRs have no precipitation nearly all the time; only CR1, CR2, and CR4 have an appreciable frequency of precipitation in this cell. In the wettest subgrid cell, these three CRs have precipitation more than half the time; in other words, most of the time these three CRs contain precipitation somewhere in the $1^{\circ}$ grid. Again, consistent 

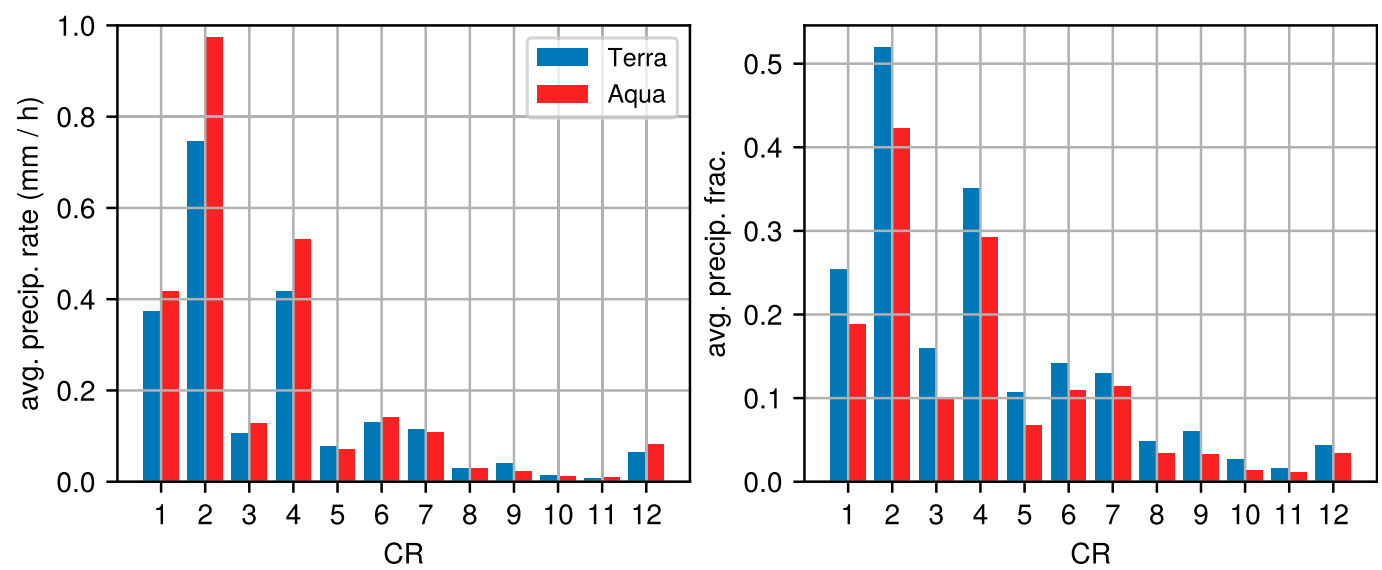

FIG. 8. Precipitation rate and precipitating fraction averaged over all composites for each MODIS CR, separated by Terra (morning) and Aqua (afternoon).

with expectations, CR2 has the highest precipitating frequency across all ranked subgrid cells, with the wettest subgrid cell precipitating $83 \%$ of the time. (A corollary of this observation is that $17 \%$ of the CR2 occurrences have no precipitation anywhere in the grid cell.) CR2 also stands out from the other CRs by having an approximately linear relationship between precipitating frequency and the ranked subgrid cell; it is however not clear if there is a physical mechanism responsible for such a linear relationship. CR7 has higher precipitating fraction than CRs 8-12 despite having similar precipitation rates, indicating that the rates of precipitating pixels are low; this suggests that it is associated with drizzle, consistent with its interpretation as a stratus regime.

This subgrid analysis of precipitation according to ranked subgrid cells showed that, in the wettest subgrid cells, CR1, CR2, and CR4 have substantial average precipitation that are nonzero most of the time. As expected, organized convection (CR2) has the highest precipitation rate and precipitating fraction across all subgrid cells. Isolated convection (CR1) also produces intense precipitation, but tends to be more sporadic than summer extratropical storms (CR4). These three atmospheric systems have precipitation within the $1^{\circ}$ grid most of the time.

\section{d. Morning and afternoon precipitation}

In the previous sections, we showed results combined from Terra and Aqua. However, Terra has an equator crossing time of 1030 local time and Aqua has an equator crossing time of 1330 local time. As such, looking at the composites separately can provide a snapshot of the morning and the afternoon subgrid precipitation properties of the CRs. Previous studies have characterized the diurnal cycle of convection and precipitation in the tropics, demonstrating, for example, that, in the afternoon over land, mesoscale convective systems occur most frequently (Tan and Jakob 2013) and produce peak precipitation (Nesbitt and Zipser 2003). The focus of this section is to draw inferences on the difference between morning and afternoon subgrid precipitation properties of the CRs.

Figure 8 shows the average precipitation rate and the average precipitating fraction for each CR, separately for Terra and Aqua. The relative differences between CRs are similar between observations in the morning and afternoon. In other words, which CR a grid cell belongs to has a stronger effect than whether it is morning or afternoon. Between Terra and Aqua, the afternoon $\mathrm{CR}$ is generally associated with heavier precipitation and a lower precipitating fraction. One reason for the higher precipitation rates in the afternoon is associated with the diurnal cycle of convection, which produces more intense precipitation later in the day. Only CR5, CR7, CR9, and CR10 have higher average precipitation rates in the morning, likely because they represent environments that are generally nonconvective. However, another reason for heavier precipitation over a smaller area in the afternoon may be attributed to a bias in the source of IMERG for Aqua CRs. As mentioned in section $2 \mathrm{~b}$, the majority of the precipitation associated with Aqua CRs is retrieved by AMSR2. As AMSR2 has one of the highest resolutions in the GPM constellation, it is able to resolve precipitation at a finer scale than most other sensors, leading to a higher precipitation rate with lower precipitating fraction. This is consistent with the TerraAqua differences in Fig. 8. However, it is unlikely that this alone explains all the differences, because 1) this bias should increase the afternoon precipitation rates of all CRs, yet four CRs exhibit weaker afternoon 
precipitation; and 2) when the analysis was repeated with 3-h slices of CR occurrences (thereby increasing the proportion of precipitation observations from other sensors that are composited to Aqua CRs), the average precipitation rates were still slightly higher despite a comparable precipitating fraction between Terra and Aqua (not shown). These two observations suggest that, while the bias in precipitation source may be a factor in the Terra-Aqua difference in Fig. 8, the diurnal cycle also contributes to the enhanced precipitation rates of the afternoon overpass.

We can further elicit insights into the subgrid structure of the morning-afternoon difference by observing the ratio of the average precipitation rates of Terra to Aqua in each ranked subgrid cell (Fig. 9). Here, values below 1 indicate that Terra has a higher average precipitation rate than Aqua, and vice versa. While variations between CRs exist, this ratio generally increases with subgrid cell rank, with many CRs starting off at a ratio below 1 in the driest subgrid cell and ending at a ratio above 1 in the wettest subgrid cell. This suggests that the diurnal development of the subgrid precipitation in these CRs involves an intensification in the wettest grid cell and a weakening in the driest grid cell, although, as the preceding discussion indicated, the precipitation source bias may explain part of the observed difference.

For CR2 and CR4, the range of ratios between Terra and Aqua is smaller than for other CRs. This is perhaps a reflection of the long lifetime of organized convection (CR2) and extratropical storms (CR4), which can easily persist over a single day and thus are less affected by the diurnal cycle. Similarly, for CR7, the Terra-Aqua ratio is just below 1 over most of the ranked subgrid cells, which is consistent with its extratropical stratus nature: its light precipitation does not display significant diurnal variation. Notably, CRs 8-10 almost always have lower precipitation rates in Aqua than in Terra, likely reflecting the inhibiting effects of insolation on these predominantly stratocumulus cloud fields. Likewise, CR5 has less precipitation in the afternoon in all but the wettest grid boxes, although the cause for such a diurnal behavior in winter extratropical storms is unclear.

Separating Terra and Aqua in the analysis can provide a glimpse of the difference of the precipitation properties between morning (Terra) and afternoon (Aqua). For the majority of the CRs, precipitation is more intense but over smaller areas in the afternoon. This is partly due to the diurnal cycle of convection and partly due to the Aqua CR bias for the high-resolution AMSR2 in IMERG. Comparing the averaged precipitation rates in the morning to the afternoon in each ranked subgrid cell, many CRs showed an intensification

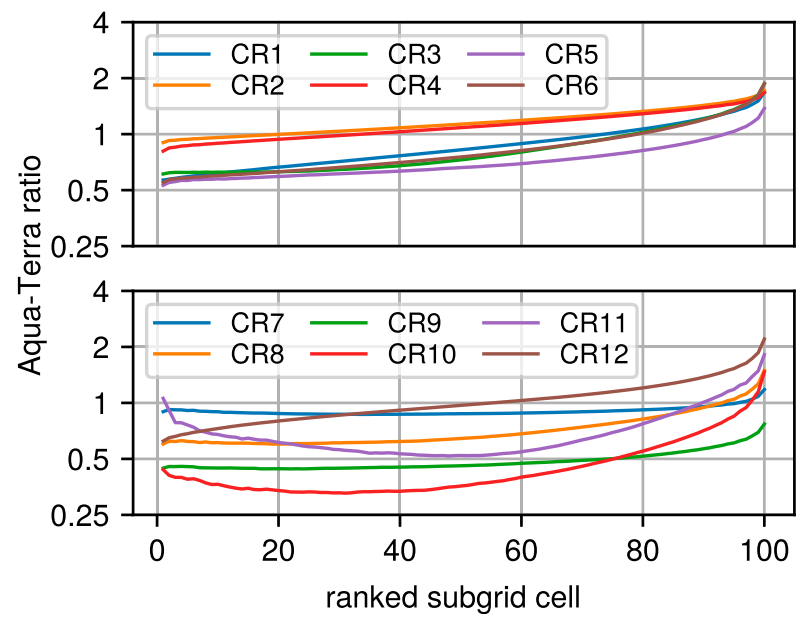

FIG. 9. Ratio of average precipitation rate of Aqua (afternoon) to Terra (morning) in ranked subgrid cells for each MODIS CR. Rank 1 is the driest subgrid cell and rank 100 is the wettest subgrid cell. Ratios below one indicate a higher average precipitation rate for Terra than for Aqua, and vice versa.

in the wettest subgrid cell and a weakening in the driest subgrid cell. For organized convection (CR2) and summer extratropical storms (CR4), the difference between morning and afternoon is small, likely reflecting the long-lived nature of such systems. The stratus regime (CR7), on the other hand, does not exhibit much difference in precipitation between morning and afternoon, while precipitation in the stratocumulus regimes (CR8-10) is generally more intense in the morning than the afternoon.

\section{Synthesis of precipitation properties of key systems}

In this study of subgrid precipitation, CR2, representing organized convection, was found to play a dominant role in tropical and midlatitude precipitation. A classic conceptual image of organized convection is a collection of intense convective cores surrounded by widespread stratiform anvils (e.g., Houze 1989, 2004). Previous studies have consistently demonstrated that organized convection produces the largest amount of precipitation at the mesoscale lengths of $\sim 100 \mathrm{~km}$ (Moncrieff 2010; Tan et al. 2013; Rossow et al. 2013), with a significant fraction coming from stratiform precipitation (Jakob and Schumacher 2008; Houze et al. 2015). Our results reveal that organized convection not only has the highest precipitation rates, but also an unusually high precipitating fraction, either according to analyses of its subgrid precipitation distribution (section $3 a)$ or its ranked subgrid properties (section 3c). For the same precipitating fraction, organized convection has 
similar grid-mean precipitation rate as isolated convection (CR1), suggesting that it is the higher precipitation coverage within the $1^{\circ}$ grid cell by the stratiform precipitation that drives its high grid-mean precipitation rates. Even so, CR2 does not have near- $100 \%$ precipitation fraction all the time; on average, only half the grid cell is precipitating (Fig. 5). In fact, the likelihood of having a low precipitating fraction and having a high precipitating fraction is about the same. Therefore, the subgrid precipitation structure of organized convection, as represented by CR2, can vary considerably from the conceptual image. While organized convection is typically associated with the tropics, Fig. 2 showed that CR2 occurs in the midlatitudes as well. Restricting the analysis to $\pm 30^{\circ}$ latitudes does not change its precipitation properties appreciably (not shown), indicating that these midlatitude occurrences of CR2 have similar properties as their tropical counterparts and are probably representative of organized convection as well.

Our results also gave some insights into the nature of isolated convection as represented by $\mathrm{CR} 1$, in comparison to more organized states of convection. While isolated convection has lower grid-mean precipitation rate than organized convection, this is largely due to its lower precipitating fraction overall (Fig. 5). When comparing the same precipitating fraction, isolated convection actually has precipitation rates comparable to organized convection (Fig. 6; section 3b). This view is consistent with Jin et al. (2018), who found a strong association between deep convective clouds and heavy rainfall. In terms of its precipitation structure, an analysis of its ranked subgrid cells suggests that isolated convection can be intense but occupies a smaller fraction of the grid cell (section 3c). Therefore, isolated convection as represented by $\mathrm{CR} 1$ can produce intense precipitation, but its small areal coverage limits its overall impact compared to other systems such as those represented by CR2 and CR4.

This study also sheds light on differences in atmospheric systems that may otherwise appear similar. For example, CR4 and CR5, both representing extratropical storms, have similar mean cloud patterns and geographical distributions, although CR4 occurs mostly in summer whereas CR5 occurs mostly in winter (Oreopoulos et al. 2017a). However, our results showed that their subgrid precipitation differs to a significant degree. Summer extratropical storms are associated with a much higher precipitating fraction and intensity, second only to organized convection (section 3a). On the other hand, winter extratropical storms have a low precipitating fraction and intensity, even in the wettest subgrid cell within the system (section 3c). One contributing factor to this difference is the higher likelihood that precipitation in CR5 is snowfall, which is generally less intense due to the lower moisture carrying capacity of cold air, although the uncertainty and underestimation associated with the retrieval of frozen precipitation may be a factor in itself.

\section{Conclusions}

MODIS CRs represent archetypal systems in the global atmosphere identified based on their cloud signatures. In this study, we leveraged the high resolution of IMERG to study the subgrid precipitation properties of these systems. With 100 spatial subgrid cells, we investigated the grid-mean precipitation rates and precipitating fractions (section 3a), their relationships (section $3 b$ ), the subgrid precipitation structures (section 3c), and the morning-afternoon differences in precipitation (section $3 \mathrm{~d}$ ).

We found that organized convection (CR2) is associated with the highest grid-mean precipitation rates and precipitating fractions, but with substantial variability between difference occurrences. Even so, on average only about half of the $1^{\circ}$ grid of this near-complete overcast system is precipitating, revealing the contrast between precipitation and cloud coverage. By comparing its precipitation rates and precipitating fractions with isolated convection, we inferred that it is the stratiform precipitation with high fractional coverage that is driving the intense precipitation of organized convection. Following organized convection, summer extratropical storms (CR4) are associated with the next highest precipitation rates and fractions, which are different from their winter counterparts (CR5) despite the similar cloud patterns and geographical distribution, largely due to higher precipitating fractions. Isolated convection (CR1) can produce precipitation within the grid that is as intense as organized convection, but its smaller coverage over the grid leads to lower grid-mean precipitation rates. These three atmospheric systemsorganized convection, isolated convection, and summer extratropical storms-have at least some precipitation within the grid more than half the time. Occurring about three-quarters of the time are systems that are generally considered dry (CR7-12), although there is a small chance of precipitation within a small portion of the grid. Across all systems, the grid-mean precipitation rate scales with precipitating fraction in a faster-than-linear relationship for all except two of the stratocumulus systems (CR8 and CR9), possibly as a consequence of interactions between the cloud-precipitation system and the environment. Comparing Terra to Aqua suggests that precipitation tends to be heavier in the afternoon for most systems, although this result is 
TABLE 2. Summary of subgrid precipitation properties of the physical systems as represented by the MODIS CRs, listing the grid-mean precipitation rates, average precipitating fractions, and contributions to total precipitation, as well as the salient features of the subgrid precipitation pattern.

\begin{tabular}{|c|c|c|c|c|c|}
\hline & Interpretation & $\begin{array}{l}\text { Mean precipitation } \\
\text { rate }\left(\mathrm{mm} \mathrm{h}^{-1}\right)\end{array}$ & $\begin{array}{l}\text { Avg precipitation } \\
\text { fraction }\end{array}$ & Contribution (\%) & Subgrid precipitation structure \\
\hline CR1 & Isolated convection & 0.393 & 0.227 & 14.9 & $\begin{array}{l}\text { Very intense but sporadic } \\
\text { precipitation, moderate } \\
\text { precipitating fraction }\end{array}$ \\
\hline $\mathrm{CR} 2$ & Organized convection & 0.862 & 0.470 & 25.7 & $\begin{array}{l}\text { Very intense precipitation } \\
\text { and over large area; high } \\
\text { precipitating fraction in general }\end{array}$ \\
\hline CR3 & Less organized convection & 0.118 & 0.127 & 5.9 & $\begin{array}{l}\text { Low area-averaged precipitation } \\
\text { due to small precipitating area, } \\
\text { but can have intense isolated } \\
\text { precipitation }\end{array}$ \\
\hline CR4 & Summer extratropical storms & 0.480 & 0.319 & 14.7 & $\begin{array}{l}\text { Generally moderate precipitation } \\
\text { rate but with high area fraction }\end{array}$ \\
\hline CR5 & Winter extratropical storms & 0.074 & 0.083 & 2.1 & $\begin{array}{l}\text { Generally low precipitation rate } \\
\text { and low area fraction }\end{array}$ \\
\hline CR6 & Congestus and nimbostratus & 0.136 & 0.126 & 5.9 & $\begin{array}{l}\text { Low area-averaged precipitation } \\
\text { with small precipitating fraction } \\
\text { and low intensity }\end{array}$ \\
\hline CR7 & Extratropical stratus & 0.112 & 0.124 & 1.8 & $\begin{array}{l}\text { Low precipitation rate with drizzle } \\
\text { over small areas }\end{array}$ \\
\hline CR8 & Stratocumulus and cumulus & 0.030 & 0.042 & 1.1 & $\begin{array}{l}\text { Generally dry; heavier in morning } \\
\text { than afternoon }\end{array}$ \\
\hline CR9 & Shallow marine stratocumulus & 0.032 & 0.047 & 1.6 & $\begin{array}{l}\text { Generally dry; heavier in morning } \\
\text { than afternoon }\end{array}$ \\
\hline CR10 & $\begin{array}{l}\text { Decaying stratocumulus and } \\
\text { cumulus }\end{array}$ & 0.013 & 0.020 & 0.8 & $\begin{array}{l}\text { Generally dry; heavier in morning } \\
\text { than afternoon }\end{array}$ \\
\hline CR11 & Shallow and trade cumulus & 0.008 & 0.013 & 0.8 & Generally dry \\
\hline CR12 & Low cloud fraction regime & 0.074 & 0.039 & 24.7 & $\begin{array}{l}\text { Generally dry, but may possess a } \\
\text { subregime with intense precipitation }\end{array}$ \\
\hline
\end{tabular}

complicated by the Aqua bias for the high-resolution AMSR2 in IMERG. Exceptions to this diurnal behavior include the stratus regime (CR7), which does not show any difference between morning and afternoon in its occasional light precipitation, and the stratocumulus regimes (CRs 8-10), which on average produce more precipitation in the morning than in the afternoon.

CRs are statistical entities derived from satellite observations; they are useful classifications of complex cloud fields. We argue that their value comes from their correspondence to actual physical systems in the global atmosphere and therefore we should ultimately view them not just as cloud patterns but rather as proxies for different atmospheric systems. It is under this rationale that they are sometimes called "weather states," although we avoid this term so as to be explicit about their origins and acknowledge potential imperfections in correspondence. Many of the CRs are associated with unique precipitation structure and distribution, but some have very similar precipitation characteristics. While precipitation is not the only trait that should receive attention in interpreting the nature of cloudiness in a $\mathrm{CR}$, these CRs may be representing processes that are similar in terms of precipitation. Hence, the guiding aim of this study is to improve simultaneously the characterization of the atmospheric systems the CRs represent and our understanding of the precipitation patterns associated with these systems.

Table 2 summarizes the key subgrid precipitation structure of the CRs, along with a quantification of their grid-mean precipitation rates, average precipitating fractions, and contributions to total precipitation (which is a function of precipitation rate and relative frequency of occurrence). These subgrid precipitation properties are consistent with existing literature that focused on the grid-mean precipitation in the tropics. For example, Lee et al. (2013), Rossow et al. (2013), and Tan et al. (2013) all found that organized convection is associated with exceptionally high rainfall; here, we further showed that its high precipitating fraction is a large contributing factor. This high precipitating fraction is consistent with the results of Jakob and Schumacher (2008), who 
examined daily CRs in the tropical west Pacific using instantaneous retrievals of precipitation from overpasses of the Tropical Rainfall Measuring Mission Precipitation Radar. Tan et al. (2013) also identified a congestus regime with lower precipitation, which again is consistent with our results (CR6); in addition, our results revealed that this is caused by its low intensity and small precipitating fraction. On the other hand, isolated convection (CR1) is a regime that is not present in ISCCP or even MODIS Collection 5 (Oreopoulos et al. 2014). Yet, its intense but sporadic precipitation pattern distinguishes it from all other regimes, justifying its inclusion in a global cloud regime dataset. Finally, there is compelling evidence that CR12 can be further split into subregimes, in line with the observations in Oreopoulos et al. (2017a). Even though it is generally a dry regime, CR12 has significant contribution to the total precipitation - on par with organized convectionby virtue of its very frequent occurrence $(41 \%$ of the time).

There are two known limitations in our approach. First, the daily time resolution of the MODIS CRs meant that an imperfect scheme to separate them into half-hour slices using mean solar zenith angle had to be implemented to reduce geolocation error in compositing with IMERG. While this is better than using daily CRs, grid cells at higher latitudes may contain observations from different swaths and are not perfectly amenable to this technique, although this undesirable effect is mitigated by remaining within $\pm 60^{\circ}$ latitudes in this study. However, we do not expect our conclusions to be affected by this shortcoming for several reasons (section 2c). A second limitation comes from the distortion of the actual area of the grid cell at high latitudes. A grid cell at $60^{\circ}$ latitude has an area half that of a grid cell at the equator. This effect, a consequence of using equal-angle grids, affects IMERG more than MODIS, since precipitation rates can be highly dependent on scale. In the absence of alternative datasets, we opted to restrict our analysis to $\pm 60^{\circ}$ latitudes to limit errors from this distortion, which from our experience should be reasonably well constrained.

It has been 15 years since the introduction of the cloud regime concept in Jakob and Tselioudis (2003), and this study adds to the growing understanding of their properties and, more importantly, the atmospheric systems they represent. In particular, this study goes beyond the grid-mean properties and peers into the subgrid structure of precipitation to expand on our characterization of the CRs. Based on our results, it is clear that the CRs represent distinct atmospheric systems, and we encourage their wider use for improving our understanding of the global climate system.
Acknowledgments. The authors are grateful for the contributions of Nayeong Cho in providing the MODIS CR datasets and the Terra and Aqua UTC times derived from the mean solar zenith angle to separate them into half-hour slices. The authors also thank three anonymous reviewers and the editor Professor Joel Norris, who have identified shortcomings in the previous manuscript and thus helped refine the study. The authors acknowledge support from the NASA MEaSUREs (NNH17ZDA001N-MEASURES) and PMM (NNH18ZDA001N-PMMST) funding. Codes used to perform the analysis can be accessed online at https:// github.com/JacksonTanBS/2019_JCLI_CR-precip/.

\section{REFERENCES}

Bodas-Salcedo, A., K. D. Williams, P. R. Field, and A. P. Lock, 2012: The surface downwelling solar radiation surplus over the Southern Ocean in the Met Office Model: The role of midlatitude cyclone clouds. J. Climate, 25, 7467-7486, https:// doi.org/10.1175/JCLI-D-11-00702.1.

_ over the Southern Ocean in CFMIP2 models. J. Climate, 27, 41-56, https://doi.org/10.1175/JCLI-D-13-00169.1.

Chen, Y., and A. D. Del Genio, 2009: Evaluation of tropical cloud regimes in observations and a general circulation model. Climate Dyn., 32, 355-369, https://doi.org/10.1007/ s00382-008-0386-6.

Feng, Z., S. Hagos, A. K. Rowe, C. D. Burleyson, M. N. Martini, and S. P. de Szoeke, 2015: Mechanisms of convective cloud organization by cold pools over tropical warm ocean during the AMIE/DYNAMO field campaign. J. Adv. Model. Earth Syst., 7, 357-381, https://doi.org/10.1002/2014MS000384.

Gordon, N. D., J. R. Norris, C. P. Weaver, and S. A. Klein, 2005: Cluster analysis of cloud regimes and characteristic dynamics of midlatitude synoptic systems in observations and a model. J. Geophys. Res., 110, D15S17, https://doi.org/10.1029/ 2004JD005027.

Handlos, Z. J., and L. E. Back, 2014: Estimating vertical motion profile shape within tropical weather states over the oceans. J. Climate, 27, 7667-7686, https://doi.org/10.1175/JCLI-D-13-00602.1.

Haynes, J. M., C. Jakob, W. B. Rossow, G. Tselioudis, and J. Brown, 2011: Major characteristics of Southern Ocean cloud regimes and their effects on the energy budget. J. Climate, $\mathbf{2 4}$ 5061-5080, https://doi.org/10.1175/2011JCLI4052.1.

Hohenegger, C., and B. Stevens, 2013: Preconditioning deep convection with cumulus congestus. J. Atmos. Sci., 70, 448-464, https://doi.org/10.1175/JAS-D-12-089.1.

Houze, R. A., 1989: Observed structure of mesoscale convective systems and implications for large-scale heating. Quart. J. Roy. Meteor. Soc., 115, 425-461, https://doi.org/10.1002/qj.49711548702.

_, 2004: Mesoscale convective systems. Rev. Geophys., 42, RG4003, https://doi.org/10.1029/2004RG000150.

— K. L. Rasmussen, M. D. Zuluaga, and S. R. Brodzik, 2015: The variable nature of convection in the tropics and subtropics: A legacy of 16 years of the Tropical Rainfall Measuring Mission satellite. Rev. Geophys., 53, 994-1021, https:// doi.org/10.1002/2015RG000488.

Hubanks, P., S. Platnick, M. King, and B. Ridgway, 2018: MODIS Atmosphere L3 Gridded Product Algorithm Theoretical Basis 
Document (ATBD) \& Users Guide. MODIS Atmosphere Group, 122 pp., https://modis-images.gsfc.nasa.gov/_docs/ L3_ATBD_C6.pdf.

Huffman, G. J., and Coauthors, 2018: GPM Integrated Multi-Satellite Retrievals for GPM (IMERG) Algorithm Theoretical Basis Document (ATBD) v5.2, NASA, 31 pp., https:/pmm.nasa.gov/ resources/documents/gpm-integrated-multi-satellite-retrievalsgpm-imerg-algorithm-theoretical-basis-

Jakob, C., and G. Tselioudis, 2003: Objective identification of cloud regimes in the tropical western Pacific. Geophys. Res. Lett., 30, 2082, https://doi.org/10.1029/2003GL018367.

_ , and C. Schumacher, 2008: Precipitation and latent heating characteristics of the major tropical western Pacific cloud regimes. J. Climate, 21, 4348-4364, https://doi.org/10.1175/ 2008JCLI2122.1.

- - G. Tselioudis, and T. Hume, 2005: The radiative, cloud, and thermodynamic properties of the major tropical western $\mathrm{Pa}$ cific cloud regimes. J. Climate, 18, 1203-1215, https://doi.org/ 10.1175/JCLI3326.1.

Jin, D., L. Oreopoulos, and D. Lee, 2017: Regime-based evaluation of cloudiness in CMIP5 models. Climate Dyn., 48, 89-112, https://doi.org/10.1007/s00382-016-3064-0.

,,,--- N. Cho, and J. Tan, 2018: Contrasting the covariability of daytime cloud and precipitation over tropical land and ocean. Atmos. Chem. Phys., 18, 3065-3082, https:// doi.org/10.5194/acp-18-3065-2018.

King, M. D., S. Platnick, W. P. Menzel, S. A. Ackerman, and P. A Hubanks, 2013: Spatial and temporal distribution of clouds observed by MODIS onboard the Terra and Aqua satellites. IEEE Trans. Geosci. Remote Sens., 51, 3826-3852, https:// doi.org/10.1109/TGRS.2012.2227333.

Lee, D., L. Oreopoulos, G. J. Huffman, W. B. Rossow, and I.-S. Kang, 2013: The precipitation characteristics of ISCCP tropical weather states. J. Climate, 26, 772-788, https://doi.org/ 10.1175/JCLI-D-11-00718.1.

Leinonen, J., M. D. Lebsock, L. Oreopoulos, and N. Cho, 2016: Interregional differences in MODIS-derived cloud regimes. J. Geophys. Res. Atmos., 121, 11 648-11 665, https://doi.org/ 10.1002/2016JD025193.

Li, W., C. Schumacher, and S. A. McFarlane, 2013: Radiative heating of the ISCCP upper level cloud regimes and its impact on the large-scale tropical circulation. J. Geophys. Res. Atmos., 118, 592-604, https://doi.org/10.1002/jgrd.50114.

Mason, S., C. Jakob, A. Protat, and J. Delanoë, 2014: Characterizing observed midtopped cloud regimes associated with Southern Ocean shortwave radiation biases. J. Climate, 27, 6189-6203, https://doi.org/10.1175/JCLI-D-14-00139.1.

, J. K. Fletcher, J. M. Haynes, C. Franklin, A. Protat, and C. Jakob, 2015: A hybrid cloud regime methodology used to evaluate Southern Ocean cloud and shortwave radiation errors in ACCESS. J. Climate, 28, 6001-6018, https://doi.org/ 10.1175/JCLI-D-14-00846.1.

Mekonnen, A., and W. B. Rossow, 2011: The interaction between deep convection and easterly waves over tropical North Africa: A weather state perspective. J. Climate, 24, 4276-4294, https://doi.org/10.1175/2011JCLI3900.1.

_ and - 2018: The interaction between deep convection and easterly wave activity over Africa: Convective transitions and mechanisms. Mon. Wea. Rev., 146, 1945-1961, https://doi.org/ 10.1175/MWR-D-17-0217.1.

Moncrieff, M. W., 2010: The multiscale organization of moist convection and the intersection of weather and climate. Climate Dynamics: Why Does Climate Vary?, Geophys. Monogr.,
Vol. 189, Amer. Geophys. Union, 3-26, https://doi.org/ 10.1029/2008GM000838.

Nesbitt, S. W., and E. J. Zipser, 2003: The diurnal cycle of rainfall and convective intensity according to three years of TRMM measurements. J. Climate, 16, 1456-1475, https://doi.org/ 10.1175/1520-0442-16.10.1456.

Oreopoulos, L., and W. B. Rossow, 2011: The cloud radiative effects of International Satellite Cloud Climatology Project weather states. J. Geophys. Res., 116, D12202, https://doi.org/ 10.1029/2010JD015472.

- N. Cho, D. Lee, S. Kato, and G. J. Huffman, 2014: An examination of the nature of global MODIS cloud regimes. J. Geophys. Res. Atmos., 119, 8362-8383, https://doi.org/ 10.1002/2013JD021409.

,$--\ldots$, and,- 2016 : Radiative effects of global MODIS cloud regimes. J. Geophys. Res. Atmos., 121, 22992317, https://doi.org/10.1002/2015JD024502.

$\ldots, \ldots$, and $-2017 \mathrm{a}$ : New insights about cloud vertical structure from CloudSat and CALIPSO observations: A new look at cloud vertical structure. J. Geophys. Res. Atmos., 122, 9280-9300, https://doi.org/10.1002/2017JD026629.

,-- , and $-2017 \mathrm{~b}$ : Using MODIS cloud regimes to sort diagnostic signals of aerosol-cloud-precipitation interactions. J. Geophys. Res. Atmos., 122, 5416-5440, https://doi.org/ 10.1002/2016JD026120.

Rossow, W. B., G. Tselioudis, A. Polak, and C. Jakob, 2005: Tropical climate described as a distribution of weather states indicated by distinct mesoscale cloud property mixtures. Geophys. Res. Lett., 32, L21812, https://doi.org/ 10.1029/2005GL024584.

_ A. Mekonnen, C. Pearl, and W. Goncalves, 2013: Tropical precipitation extremes. J. Climate, 26, 1457-1466, https:// doi.org/10.1175/JCLI-D-11-00725.1.

—, Y. Zhang, and G. Tselioudis, 2016: Atmospheric diabatic heating in different weather states and the general circulation. J. Climate, 29, 1059-1065, https://doi.org/10.1175/JCLI-D-15-0760.1.

Skofronick-Jackson, G., and Coauthors, 2017: The Global Precipitation Measurement (GPM) mission for science and society. Bull. Amer. Meteor. Soc., 98, 1679-1695, https://doi.org/ 10.1175/BAMS-D-15-00306.1.

Sohn, B. J., S.-W. Yeh, J. Schmetz, and H.-J. Song, 2013: Observational evidences of Walker circulation change over the last 30 years contrasting with GCM results. Climate Dyn., 40, 1721-1732, https://doi.org/10.1007/s00382-012-1484-z.

Stachnik, J. P., C. Schumacher, and P. E. Ciesielski, 2013: Total heating characteristics of the ISCCP tropical and subtropical cloud regimes. J. Climate, 26, 7097-7116, https://doi.org/ 10.1175/JCLI-D-12-00673.1.

Tan, J., and C. Jakob, 2013: A three-hourly data set of the state of tropical convection based on cloud regimes. Geophys. Res. Lett., 40, 1415-1419, https://doi.org/10.1002/grl.50294.

,-- , and T. P. Lane, 2013: On the identification of the largescale properties of tropical convection using cloud regimes. J. Climate, 26, 6618-6632, https://doi.org/10.1175/ JCLI-D-12-00624.1.

,,-- W. B. Rossow, and G. Tselioudis, 2015: Increases in tropical rainfall driven by changes in frequency of organized deep convection. Nature, 519, 451-454, https://doi.org/10.1038/ nature14339.

, W. A. Petersen, and A. Tokay, 2016: A novel approach to identify sources of errors in IMERG for GPM ground validation. J. Hydrometeor., 17, 2477-2491, https://doi.org/10.1175/ JHM-D-16-0079.1. 
L. Oreopoulos, C. Jakob, and D. Jin, 2018a: Evaluating rainfall errors in global climate models through cloud regimes. Climate Dyn., 50, 3301-3314, https://doi.org/10.1007/ s00382-017-3806-7.

—, W. A. Petersen, G. Kirchengast, D. C. Goodrich, and D. B. Wolff, 2018b: Evaluation of Global Precipitation Measurement rainfall estimates against three dense gauge networks. J. Hydrometeor., 19, 517-532, https://doi.org/10.1175/ JHM-D-17-0174.1.

Tromeur, E., and W. B. Rossow, 2010: Interaction of tropical deep convection with the large-scale circulation in the MJO. J. Climate, 23, 1837-1853, https://doi.org/10.1175/ 2009JCLI3240.1.

Tselioudis, G., and W. B. Rossow, 2011: Time scales of variability of the tropical atmosphere derived from cloud-defined weather states. J. Climate, 24, 602-608, https://doi.org/10.1175/ 2010JCLI3574.1.

— , E. Tromeur, W. B. Rossow, and C. S. Zerefos, 2010: Decadal changes in tropical convection suggest effects on stratospheric water vapor. Geophys. Res. Lett., 37, L14806, https://doi.org/ 10.1029/2010GL044092.

, W. Rossow, Y. Zhang, and D. Konsta, 2013: Global weather states and their properties from passive and active satellite cloud retrievals. J. Climate, 26, 7734-7746, https://doi.org/ 10.1175/JCLI-D-13-00024.1.
Tsushima, Y., M. A. Ringer, M. J. Webb, and K. D. Williams, 2013: Quantitative evaluation of the seasonal variations in climate model cloud regimes. Climate Dyn., 41, 2679-2696, https:// doi.org/10.1007/s00382-012-1609-4.

_ _ and Coauthors, 2016: Robustness, uncertainties, and emergent constraints in the radiative responses of stratocumulus cloud regimes to future warming. Climate Dyn., 46, 3025-3039, https://doi.org/10.1007/s00382-015-2750-7.

Wen, Y., A. Behrangi, B. Lambrigtsen, and P.-E. Kirstetter, 2016: Evaluation and uncertainty estimation of the latest radar and satellite snowfall products using SNOTEL measurements over mountainous regions in western United States. Remote Sens., 8, 904, https://doi.org/10.3390/ rs8110904.

Williams, K. D., and G. Tselioudis, 2007: GCM intercomparison of global cloud regimes: Present-day evaluation and climate change response. Climate Dyn., 29, 231-250, https://doi.org/ 10.1007/s00382-007-0232-2.

— and M. J. Webb, 2009: A quantitative performance assessment of cloud regimes in climate models. Climate Dyn., $\mathbf{3 3}$, 141-157, https://doi.org/10.1007/s00382-008-0443-1.

—, C. A. Senior, A. Slingo, and J. F. B. Mitchell, 2005: Towards evaluating cloud response to climate change using clustering technique identification of cloud regimes. Climate Dyn., 24, 701-719, https://doi.org/10.1007/s00382-004-0512-z. 